\title{
Relationship between bronchial asthma and glucocorticoid receptor gene bcl-I single nucleotide polymorphism
}

\author{
Zhelin Yun ${ }^{1}$, Dongmei Wang*2, Yanjie $Q u^{2}$ \\ ${ }^{1}$ The Third Affiliated Hospital of Inner Mongolia Medical University, Baotou, Inner Mongolia, China \\ ${ }^{2}$ The Forth Hospital of Baotou, Baotou, Inner Mongolia, China
}

Received: May 20, 2018

DOI: $10.14725 /$ dcc.v5n3p8
Accepted: July 8, 2018

URL: http://dx.doi.org/10.14725/dcc.v5n3p8

\begin{abstract}
Objective: To investigate the relationship between bronchial asthma in children and glucocorticoid receptor (GR) gene bcl-I single nucleotide polymorphism and to analyze the relationship between bronchial asthma and the plasma cortisol level.

Methods: Polymerase chain reaction-restriction fragment length polymorphism (PCR-RFLP) techniques were used to determine the GR gene bcl-I single nucleotide polymorphism in 76 children patients with asthma and 50 healthy controls. The plasma cortisol levels were detected by radio immunoassay in two groups respectively.

Results: There were three genotypes found in bcl-I gene locus of these two groups, which were genotype CC, GG and CG. The frequencies of CC, CG, GG genotypes were $48.7 \%, 27.6 \%, 23.7 \%$ in the asthma group and 76\%, 20\%, $4 \%$ in the control group. The difference was of statistical significance $(p<.05)$. The frequency of $\mathrm{G}$ allele in the asthma group was $37.5 \%$, which was significantly higher than $14 \%$ in the control group $(p<.05)$, indicating that $\mathrm{G}$ allele was associated with asthma.

Conclusions: GR gene bcl-I polymorphism is significantly associated with the occurrence of bronchial asthma. G allele may be a susceptibility gene for steroid-resistance in asthma. Steroid-resistance has no correlation to the plasma cortisol level.
\end{abstract}

Key Words: Asthma, Glucocorticoid receptor, Gene polymorphism, Steroid-resistance

Bronchial asthma is a common and frequently-occurring disease in childhood. It is a chronic inflammatory airway disease involving various cells (such as mast cells, T cells, neutrophils, eosinophils, airway epithelial cells, etc.) and cellular components. ${ }^{[1]}$ Glucocorticoid (GC), as one of the main drugs for clinical treatment of asthma, can significantly relieve symptoms such as wheezing, cough and expectoration, and help asthma patients with quality of life. However, some patients, who have received a long-term or a large-dose steroid therapy, are still subject to poor efficacy, in which situation this type of disease is called steroid resistant asthma. ${ }^{[2]}$ The pharmacological and physiological effects of glucocorticoids need to be mediated by the glucocorticoid receptor (GR). GR gene is located at $5 q^{1-3}$, and the study ${ }^{[3]}$ indicates that a large number of genes are distributed on the long arm (5q) of chromosome 5, which may play an important role in the regulation of IgE synthesis and the development of allergy and asthma-related inflammation. Using polymerase chain reaction-restriction fragment length polymorphism (PCR-RFLP) technique, the authors determined the GR gene bcl-I single nucleotide polymorphism and explored its relationship with the occurrence of bronchial asthma, which was reported as follows.

*Correspondence: Dongmei Wang; E-mail: dcc73@ncspress.com; Address: The Forth Hospital of Baotou, Baotou, Inner Mongolia, China. 


\section{Data and methods}

\subsection{General information}

According to the criteria of "Guidelines for the Diagnosis and Prevention of Bronchial Asthma in Children" revised by the Chinese Medical Association in $2008,{ }^{[4]} 76$ cases of children who were diagnosed with asthma during outpatient visits or hospitalization in the Fourth Hospital of Baotou from October 2013 to October 2015 were selected as the asthma group. Children patients in this group, aged 4 to 15 , with an average age of $(8.97 \pm 2.93)$, contained 54 males and 22 females. 50 cases of healthy children during the same period were selected as the control group, in which children aged 5 to 16 , with an average age of (9.08 \pm 3.00 ), 35 males and 15 females. There were no significant differences in age and gender between these two groups $(p>.05) .44$ children with steroid-resistance and their parents agreed and cooperated with doctors to be treated with oral prednisone $1 \mathrm{mg} / \mathrm{kg} /$ day for 7 days. Pulmonary function tests were required to be performed before and after treatment, the standard of forced expiratory volume in one second $\left(\mathrm{FEV}_{1}\right)$ improved rate $<15 \%$ indicated that children had steroid resistant asthma. ${ }^{[5]}$

\subsection{Methods}

$2 \mathrm{~mL}$ EDTA peripheral blood (fasting blood) was required of each subject in the morning for cell and plasma separation, and then stored in a refrigerator at $-20^{\circ} \mathrm{C}$. The detection of GR gene bcl-I single nucleotide polymorphism was performed to the separated precipitations containing cellular components, with the detection of the plasma cortisol level performed to the plasma fraction.

The detection of GR gene bcl-I single nucleotide polymorphism was listed as follows: (1) Extraction of genomic DNA. DNA was extracted from mononuclear cells in the separated precipitations containing cellular components and stored at $-20^{\circ} \mathrm{C}$ for examination. (2) PCR amplification. The primers were designed according to the reference ${ }^{[6]}$ and synthesized by Sangon Biotech (Shanghai) Co., Ltd., and the upstream primer was 5'-GAGAAATTCACCCCTACCAAC-3', the downstream primer was 5'-AGAGCCCTATTCTTCAAACTG-3'. The reaction volume was $25 \mu \mathrm{l}$, including $2.5 \mu \mathrm{l} 10 \times$ buffer, 2.5 $\mu \mathrm{l} \mathrm{MgCl}_{2}, 2.0 \mu \mathrm{ldNTP}, 1 \mu \mathrm{l}$ of upstream primers and $1 \mu \mathrm{L}$ of downstream primers, $0.25 \mu \mathrm{l}$ Taq enzyme, $3 \mu \mathrm{l}$ DNA and $12.75 \mu \mathrm{l}$ double distilled water. Reaction conditions were as follows: initial denaturation at $94^{\circ} \mathrm{C}$ for $5 \mathrm{~min}$, denaturation at $94^{\circ} \mathrm{C}$ for $45 \mathrm{~s}$, annealing at $57^{\circ} \mathrm{C}$ for $45 \mathrm{~s}$, extension at $72^{\circ} \mathrm{C}$ for $45 \mathrm{~s}, 38$ cycles in total, and extension at $72^{\circ} \mathrm{C}$ for 5 min. (3) PCR product digestion. $10 \mu 1$ of PCR amplification products were taken and added with $1.2 \mu \mathrm{l}$ of bcl-I restriction endonucleases, $2 \mu \mathrm{l}$ of $10 \times$ loading buffer and $7 \mu \mathrm{L}$ of distilled water for a water bath at $37^{\circ} \mathrm{C}$ for $10 \mathrm{~h}$. (4) Electrophoresis. PCR markers were used as standard reference for DNA fragments, with electrophoresis performed by use of $2 \%$ agarose $(4.0 \mathrm{~g} / \mathrm{dl})$ ethidium bromide gel method (voltage $120 \mathrm{~V}, 20 \mathrm{~min}$ ) for imaging on the UVtransmission automated imaging analyzer. The results were recorded accordingly.

Radio immunoassay was applied to the detection of the plasma cortisol (Cor) level. The separated plasma was assayed for the cortisol level according to the instructions of Human Plasma Cortisol ELISA Kit (provided by Beijing North Institute of Biological Technology).

\subsection{Statistical methods}

SPSS16.0 statistical software was applied to statistical treatment, and the chi-square test was used in the comparison of categorical data. The measurement data were represented by mean \pm standard deviation, with $t$-test and analysis of variance used. The difference $p<.05$ was statistically significant.

\section{Results}

The results of electrophoresis of PCR amplification products were shown in Figure 1. The comparison in genotypic frequency and allele frequency of each group was shown in Table 1. The electrophoresis analysis of PCR amplification products in this study confirmed that there were three genotypes of bcl-I genes in asthma children - homozygous CC, homozygous GG and heterozygous CG. The frequency distribution of GG genotype in the asthma group was significantly higher than that in the control group $(p<.05)$; the frequency of $\mathrm{G}$ alleles was $37.5 \%$ in the asthma group, which was also significantly higher than $14 \%$ in the control group $(p<.05)$. This indicated that there was a correlation between $\mathrm{G}$ allele and the occurrence of asthma. The determination results of the plasma cortisol level in these two groups were shown in Table 2. The number of steroid-sensitive cases in CC group was 19, the number of steroid-insensitive cases was 4 and the proportion of steroid sensitivity was $82.61 \%$; in GG group and GC group were 6 cases of steroid sensitivity, 15 cases of steroid insensitivity, and the proportion of steroid sensitivity was $28.57 \%$. The proportion of steroid sensitivity in CC group was significantly higher than that in GG and GC groups $(p<.01)$. There were no significant differences in the cortisol level in different steroid therapy groups (see Table 3 ).

\section{Discussion}

\subsection{The effect of genovariation on GR gene func- tion}

The biological effects of GC need to be mediated by GR. GR, a ligand-activated endogenous transcription factor, 
mainly located in the cytoplasm, belongs to the family of nuclear receptors and has been formally named NR3C1 (nuclear receptor subfamily 3 , group C, member 1). ${ }^{[7]}$ Human NR3C1 has 10 exons in total, ${ }^{[8]}$ in which the $9^{\text {th }}$ exon can generate two types of homologous mRNA and protein isoforms (i.e., GR $\alpha$ and $\mathrm{GR} \beta$ ) by alternative splicing, and GR subunits combine with heat shock protein 90 (HSP90) and heat shock protein 70 (HSP70) to form a complex, which is inactivated; GC is diffused into the cytoplasm and bound to GR-Hsp with Hsp isolated. GC and GR complexes enter into the nucleus and bind to GRE of the target gene promoter sequence to activate or inhibit the transcriptional activity of the target gene and regulate the synthesis of protein, which is so-called "the mechanism of genomic effect" of GC. ${ }^{[9]}$ Therefore, abnormalities in protein structure or changes in gene expression caused by GR genovariation will affect the amount and the binding of receptors, thereby affecting the action of GC and resulting in causing steroidresistance. Tuckemann et al. ${ }^{[10]}$ used selective GR mutant mice to study the anti-inflammatory mechanism of steroids, and found that mice with depletion in DNA Ligases between glucocorticoid receptors showed resistance to steroid therapies. Polymorphic GR genes can also cause the over- expression of related cytokines (such as IL-4) or various key molecules inducing steroid resistance, ${ }^{[11]}$ which may be related to the decrease in GC sensitivity.

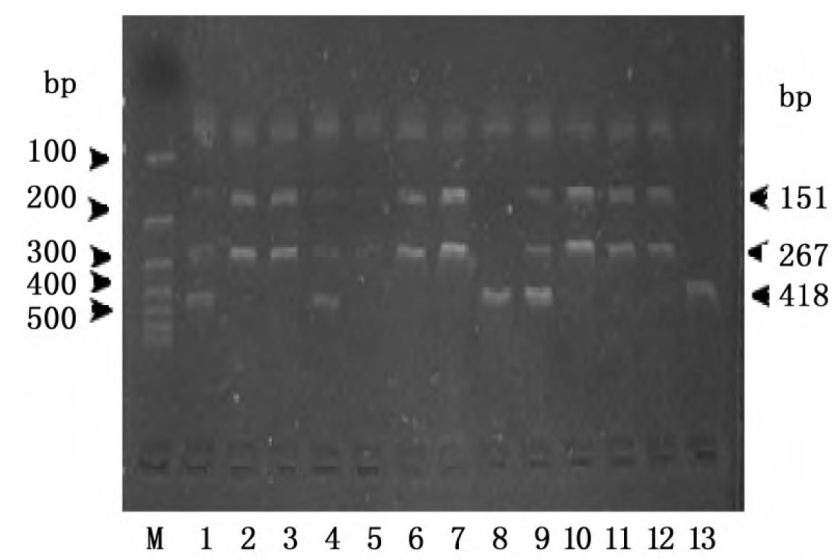

Figure 1: Electrophoresis results of PCR amplification products

Note. M stands for marker; 2, 3, 5, 6, 7, 10, 11, 12 are wild type $\mathrm{CC} ; 1,4,9$ are heterozygous $\mathrm{CG} ; 8,13$ are mutant type GG.

Table 1: Comparison in genotypic frequency and allele frequency between the asthma group and the control group at bcl-I locus [n (\%)]

\begin{tabular}{lccccccc}
\hline \multirow{2}{*}{ Group } & \multirow{2}{*}{} & \multicolumn{3}{c}{ Genotypic Frequency } & & \multicolumn{2}{c}{ Allele Frequency } \\
\cline { 3 - 5 } & & CC & CG & GG & & C & G \\
\hline Asthma Group & 76 & $37(48.7)^{*}$ & $21(27.6)^{*}$ & $18(23.7)^{*}$ & & $95(62.5)^{*}$ & $57(37.5)^{*}$ \\
Control Group & 50 & $38(76.0)$ & $10(20.0)$ & $2(4.0)$ & & $86(86.0)$ & $14(14.0)$ \\
\hline
\end{tabular}

Note. In comparison with the control group, ${ }^{*} p<.05$

Table 2: Comparison in the distribution of bcl-I polymorphism and the plasma cortisol level in 2 groups (ng/ml)

\begin{tabular}{llllll}
\hline Group & $\mathbf{n}$ & Plasma Cortisol Level & CC & CG & GG \\
\hline Asthma Group & 76 & $123.74 \pm 40.40$ & $119.60 \pm 44.8$ & $124.78 \pm 42.60$ & $130.97 \pm 26.40$ \\
Control Group & 50 & $109.35 \pm 46.19$ & $103.40 \pm 47.3$ & $123.91 \pm 39.21$ & $150.27 \pm 32.97$ \\
\hline
\end{tabular}

Table 3: Relationship between steroid sensitivity and cortisol level

\begin{tabular}{lllllll}
\hline Group & $\mathbf{n}$ & Plasma Cortisol Level X & $\sum \mathbf{X}$ & $\sum \mathbf{X}^{\mathbf{2}}$ & $\boldsymbol{\sigma}$ & $\boldsymbol{\sigma - 1}$ \\
\hline Steroid Sensitivity Group & 25 & $120.96 \pm 43.38$ & $3,024.08$ & $412,856.46$ & 43.38 & 44.28 \\
Steroid Insensitivity Group & 19 & $117.98 \pm 31.81$ & $2,241.56$ & $283,680.14$ & 31.81 & 32.68 \\
\hline
\end{tabular}

\subsection{GR gene bcl-I single nucleotide polymorphism and steroid resistance in asthma}

Hurley et al. ${ }^{[12]}$ found that GR genovariation can lead to familial glucocorticoid resistance. Studies have shown that GR genovariation can cause structural and functional abnor- malities in GR genes, leading to familial glucocorticoid resistance or acquired glucocorticoid resistance. At present, researches on GR gene polymorphism at home and abroad mainly focus on the three aspects, i.e., bcl-I, ER22/23EK and N3635 polymorphism, with a large amount of reports on both positive and negative results. 
The bcl-I polymorphism refers to a mutation at nucleotide 646 in the downstream of the $2^{\text {nd }}$ exon in GR gene, namely

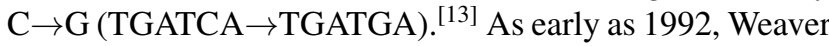
et al. ${ }^{[14]}$ firstly studied the bcl-I polymorphism and found that subjects with homozygous mutant genes of bcl-I polymorphism had a higher fasting serum insulin level and insulin resistance index. In 2006, Anja Rogausch et al. ${ }^{[15]}$ made a study on bcl-I polymorphism and smoking behavior in patients with bronchial asthma, COPD and other airway obstructive diseases, and found that the existence of this type of polymorphism was associated with the dependence of the population on nicotine and its severity. In addition, the fact that patients with pulmonary fibrosis had inconsistent responses to GC treatment made Harriet Corvol and other scholars speculate that GR gene polymorphism may induce changes in the inflammatory reaction in patients with pulmonary fibrosis, influencing the sensitivity of patients to GC. Harriet Corvol et al. ${ }^{[16]}$ detected 4 types of GR gene polymorphism (i.e., Tthlll, ER22/23EK, N363S and bcl-I) in 255 young patients with pulmonary fibrosis and followed up their disease evolution processes. It was found that in patients with bcl-l genes, $\mathrm{FEV}_{1}$ and forced vital capacity (FVC) showed a downward trend, in which GG patients showed a more significant decline trend in bcl-I than GC and $\mathrm{CC}$ patients. It was speculated from the experimental results that the bcl-I polymorphism may be related to the inflammatory reaction regulating fibrotic pulmonary tissues. It can interfere with GC to play an anti-inflammatory role normally and accelerate the exacerbation of pulmonary function in patients with pulmonary fibrosis. The potential relevance of bcl-I polymorphism in various metabolic and functional disorders in body mass index, blood pressure and cholesterol level has been extensively studied. ${ }^{[17-19]}$ Tadeusz Pietras et al. ${ }^{[6]}$ conducted a preliminary study on the relationship between the GR gene bcl-I single nucleotide polymorphism and asthma, and the results showed that the bcl-I polymorphism was associated with the resistance in asthma.

Of 76 children with asthma in this study, 44 patients agreed and cooperated with the test for steroid resistance, 19 of which showed steroid resistance consequently. By performing an analysis on GR gene bcl-I single nucleotide polymorphism, the authors found that 4 out of the 19 patients showed $\mathrm{CC}$ genotype, and the remaining 15 patients were GG and $\mathrm{CG}$ genotypes in which GR genes contained $\mathrm{G}$ alleles. However, the average cortisol level in children with steroid resistance was not increased. According to the author's analysis, allele $\mathrm{C}$ is mutated to $\mathrm{G}$, which leads to changes in GR structure and function, reduces the pharmacological effects of the binding to glucocorticoid and results in steroid resis-

\section{References}

[1] Li MH, Yin KS. Asthmology ( $2^{\text {nd }}$ ed). Beijing: People's Medical Publishing House; 2005. 1 p. tance. The bcl-I single nucleotide polymorphism is not only related to the occurrence of bronchial asthma in children, but also allele $\mathrm{G}$ may be a susceptibility gene for steroid resistance in asthma. This conclusion is consistent with the research conducted by Tadeusz Pietras et al. ${ }^{[6]}$

It is well-known that the onset of asthma is the result produced by multiple genes and factors. The relationship between the presence of genetic polymorphism at other locuses of GR gene and asthma remains to be further explored. It is necessary to further expand the amount of specimens or conduct a multi-center research with a large amount of specimens.

\section{3 bcl-I single nucleotide polymorphism, steroid resistance in asthma and plasma cortisol level}

Cortisol, in the glucocorticoid class of hormones, is mainly produced by the zona fasciculata of the adrenal cortex. It is a 21-carbon steroid hormone. Currently, glucocorticoid resistance is clinically divided into primary glucocorticoid resistance and acquired glucocorticoid resistance. The former is mostly familial, with elevated plasma cortisol levels and no Cushing syndrome, characterized by the resistance of the axis of hypothalamus-hypophysis-adrenal glands to DXMS and defects in GR affinity. Most patients with familial glucocorticoid resistance have defects in GR function due to GR genovariation. In this experiment, the plasma cortisol level was measured in 76 children with asthma and 50 healthy children, with a statistical analysis performed to the experimental results. It was found that there was no significant difference in the plasma cortisol level between different groups and different genotypes in each group, indicating that the patients showed a normal endogenous corticosteroid secretion and metabolic function, without any clinical characteristics of adrenal cortex insufficiency and manifestations of absorption disorder, metabolic acceleration and clearance speed-up etc. in glucocorticoid. It is indicated that steroid resistance in asthma is not related to the plasma cortisol level. Therefore, the authors initially consider that GR gene bcl-I single nucleotide polymorphism is an important factor leading to steroid resistance in asthma, for which allele $\mathrm{G}$ may be a susceptibility gene.

\section{Conflicts of Interest Disclosure}

The authors have no conflicts of interest related to this article.

[2] Barnes PJ. Glucocorticosteroids: current and future directions. Br J Pharmacol. 2011; 163(1): 29-43. PMid: 21198556. https ://doi. org/10.1111/j.1476-5381.2010.01199.x

[3] Theriault A, Boyd E, Harrap SB, et al. Regional chromosomal as- 
signment of the human glucocorticoid receptor gene to $5 \mathrm{q} 31$. Hum Genet. 1989; 83: 289-291. PMid: 2793174. https://doi.org/ 10.1007/BF00285175

[4] Subspecialty Group of Respiratory Diseases, Chinese Pediatric Society, Chinese Medical Association. Guidelines for the Diagnosis and Prevention of Bronchial Asthma in Children. Chinese Journal of Pediatrics. 2008; 46(10): 745-753. PMid: 19099878.

[5] Subspecialty Group of Asthma, Chinese Thoracic Society, Chinese Medical Association. Guidelines for prevention and treatment of bronchial asthma. Chinese Journal of Tuberculosis and Respiratory Diseases. 2008; 31(3): 177-185.

[6] Pietras T, Panek M. The Bcl-I single nucleotide polymorphism of the human glucocorticoid receptor gene h-GR/NR3C1 promoter in patients with bronchial asthma: pilot study. Mol Biol Rep. 2010; 38(6): 3953-3958. PMid: 21113676. https://doi.org/ 10.1007/s11033-010-0512-5

[7] Nuclear Receptors Nomenclature Committee. A unified nomenclature system for the nuclear receptor super family. Cell. 1999; 97(2): 161-163. https://doi.org/10.1016/S0092-8674(00) 80726-6

[8] Panek M, Pietras T, Kuan P, et al. The analysis of the factors influencing the development of glucocorticoid resistance in the etiopathogenesis of severe bronchial asthma. Postepy Biochem. 2010; 56(4): 373-382. PMid: 21473041

[9] Pietras T, Panek M, Kuna P, et al. Frequencies of Bcl-I, E22E, and $\mathrm{N} 363 \mathrm{~S}$ of h-GR/NR3C1 restriction fragment length polymorphisms of glucocorticoid receptor gene in Polish adult population. Med Sci Monit. 2010; 16(10): CR475-479. PMid: 20885351.

[10] Tuckermann JP, Kleiman A, Moriggl R, et al. Macrophages and neutrophils are the targets forimmune suppression by glucocorticoids in contact allergy. J ClinInvest. 2007; 117(5): 1381-1390. PMid: 17446934. https://doi.org/10.1172/JCI28034

[11] Koyano S, Saito Y, Nagano M, et al. Functional analysis of three genetic polymorphisms in the glucocorticoid receptor gene. J Pharmacol Exp Ther. 2003; 307(1): 110-116. PMid: 12954798. https : //doi.org/10.1124/jpet.103.054155
[12] Hurley DM, Katl M, Lamberts SW, et al. Familial glucocorticoid resistance caused by a splice site deletion in the human glucocorticoid receptor gene. J Clin Endocrinol Metab. 1993; 76(3): 683-689. PMid: 8445027.

[13] van Rossum EF, Koper JW, van den Beld AW, et al. Identifieation of the Bell Polymorphism in the glucocorticoid receptor gene: association with sensitivity to glucocorticoids in vivo and body mass index. Clin Endocrinol (Oxf). 2003; 59(5): 585-592. https://doi.org/ 10.1046/j.1365-2265.2003.01888.x

[14] Weaver JU, Hitman G A, KoPelman PG. An association between a Bell restriction fragment length Polymorphism of the glucoeortieoid receptor locus and hyPerinsu-linaemia in obese women. $\mathbf{J}$ Mol Endocrinol. 1992; 9(3): 295-300. PMid: 1362060. https: //doi.org/10.1677/jme.0.0090295

[15] Rogausch A, Kochen MM, Meineke C, et al. Association between the Bell glucocorticoid receptor Polymorphism and smoking in a sample of Patients with Obstructive airway disease. Addict Biol. 2007; 12(1): 93-99. PMid: 17407502. https://doi.org/10. $1111 / \mathrm{j} .1369-1600.2006 .00045 . \mathrm{x}$

[16] CorvoI H, Nathan N, Charlier C, et al. Glueocortieoid receptor gene Polymorphisms Associated with Progression of lung disease in young Patients with cystic fibrosis. Respir Res. 2007; 8(1): 88-96. PMid: 18047640. https://doi.org/10.1186/ 1465-9921-8-88

[17] Rosmond R. The glueocorticoid receptor gene and its association to metabolic syndrome. Obesity Res. 2002; 10(10): 1078-1086. PMid: 12376590. https://doi.org/10.1038/oby.2002.146

[18] Bray PJ, Cotton RG. Variations of the human glucocorticoid receptor gene (NR3C1): pathological and in vitro mutations and polymorphisms. Hum Mutat. 2003; 21(6): 557-568. PMid: 12754700. https://doi.org/10.1002/humu. 10213

[19] Maltese P, Canestrari E, Palma L, et al. High resolution melting (HRM) analysis for the detection of ER22/23EK, Bcl-I, and N363S polymorphisms of the glucocorticoid receptor gene. Steroid Biochem Mol Biol. 2009; 113(3/4/5): 269-274. 